\title{
Surgical options for full-thickness rectal prolapse: current status and institutional choice
}

\author{
Tomohide Hori, Daiki Yasukawa, Takafumi Machimoto, Yoshio Kadokawa, Toshiyuki Hata, Tatsuo Ito, \\ Shigeru Kato, Yuki Aisu, Yusuke Kimura, Yuichi Takamatsu, Taku Kitano, Tsunehiro Yoshimura
}

Tenriyorodusoudanjyo Hospital, Tenri, Japan

\begin{abstract}
Full-thickness rectal prolapse (FTRP) is generally believed to result from a sliding hernia through a pelvic fascial defect, or from rectal intussusception. The currently accepted cause is a pelvic floor disorder. Surgery is the only definitive treatment, although the ideal therapeutic option for FTRP has not been determined. Auffret reported the first FTRP surgery using a perineal approach in 1882, and rectopexy using conventional laparotomy was first described by Sudeck in 1922. Laparoscopy was first used by Bermann in 1992, and laparoscopic surgery is now used worldwide; robotic surgery was first described by Munz in 2004. Postoperative morbidity, mortality, and recurrence rates with FTRP surgery are an active research area and in this article we review previously documented surgeries and discuss the best approach for FTRP. We also introduce our institution's laparoscopic surgical technique for FTRP (laparoscopic rectopexy with posterior wrap and peritoneal closure). Therapeutic decisions must be individualized to each patient, while the surgeon's experience must also be considered.
\end{abstract}

Keywords Rectal prolapse, rectopexy, laparoscopic surgery, mesh, posterior wrap, peritoneal closure

Ann Gastroenterol 2018; 31 (1): 1-10

\section{Introduction}

Rectal prolapse is defined as a protrusion of the rectal wall outside the anus resulting from a pelvic floor disorder $[1,2]$. Full-thickness rectal prolapse (FTRP) refers to prolapse of all layers of the bowel wall; a hemorrhoidal/partial prolapse involves only the mucosa [1]. FTRP has a characteristic circular mucosal fold appearance, whereas hemorrhoidal/ partial prolapse shows radial folds [1]. FTRP is distinct from hemorrhoidal/partial prolapse $[1,3]$, and symptoms related to FTRP are often refractory to treatment and intractable [3].

Surgery is the only definitive treatment for FTRP [1,2], although the ideal therapeutic approach is a matter of debate $[1,3]$. Concomitant bladder or vaginal prolapse will complicate surgical options; therefore, we will focus on possible

Department of Digestive Surgery, Tenriyorodusoudanjyo Hospital, Tenri, Japan

Conflict of Interest: None

Correspondence to: Dr. Tomohide Hori, PhD, MD, FACS, Department of Digestive Surgery, Tenriyorodusoudanjyo Hospital, 200 Mishimacho, Tenri, Nara, 632-8552 Japan, e-mail: horitomo@tenriyorozu.jp

Received 17 July 2017; accepted 8 November 2017; published online 15 December 2017

DOI: https://doi.org/10.20524/aog.2017.0220 alternatives for surgical treatment in patients with only FTRP. In this article, we review previously documented surgeries for FTRP and discuss the best surgical options.

\section{Etiology}

The etiology of rectal prolapse is not entirely understood [1,2]. Generally, FTRP is believed to result from a sliding hernia through a pelvic fascial defect or from rectal intussusception [1,2]. Pelvic floor laxity, weak sphincter complex, redundant rectosigmoid colon, deep Douglas' pouch, pudendal neuropathy, and loose rectal fixation may play a role in FTRP [1,2]. Currently, a pelvic floor disorder is considered as the most likely cause $[2,4,5]$.

\section{Distribution}

FTRP occurs in both pediatric and adult populations and has bimodal peaks [3]. Most FTRP patients (up to >90\%) are women older than 50 years with a history of vaginal childbirth $[1,2,6,7]$. Because many populations worldwide are aging, the incidence of adult FTRP is also increasing [3]. Male FTRP patients are typically younger (20-40 years of age) [1] 
and the incidence decreases with advancing age. The incidence of FTRP is also greater among psychiatric patients and elderly nursing-home residents $[1,8]$.

\section{Symptoms and evaluation}

FTRP is a benign disease. However, the symptoms vary and include mucoid discharge, rectal bleeding (especially after defecation), tenesmus, and constipation with straining and incontinence $[1,3]$. Some symptoms are often refractory and intractable $[1,3]$.

FTRP is diagnosed based on a patient's history and physical examination [1]. FTRP can often be reduced during examination [1], and digital examination reveals a patulous anus, with diminished resting tone and squeeze pressure [1]. The most reliable diagnosis is made with the patient sitting on a commode bearing down to simulate a bowel movement [1]. FTRP is distinguished from hemorrhoidal/partial prolapse by the appearance of concentric folds [1].

The most common classification divides FTRP into three grades [2]: I: inner recto-rectal intussusception of the rectum proximal to the anal canal; II: inner recto-anal intussusception into the anal canal; and III: external prolapse of the rectum beyond the anus.

The preoperative workup in our institution routinely involves colonoscopy, in order to rule out the possibility of comorbid malignancy.

\section{History}

Auffret reported the first surgical therapy for FTRP in $1882[9,10]$, and surgery remains the only definitive treatment $[1,2]$. Therapeutic options include narrowing of the anal orifice, obliteration of Douglas' pouch, restoration of the pelvic floor, resection of redundant bowel, and suspension/ fixation of the rectum to the sacrum [1,2]. Surgical approaches include either a perineal or abdominal approach [1-3,11-13], and because FTRP is essentially a benign disease, surgical management should be individualized to balance the risk of perioperative invasiveness with the potential benefit to quality of life [14]. Abdominal procedures are preferred by most surgeons, because they are more effective and are associated with lower recurrence rates, even in older patients $[1,3,15]$. However, general anesthesia, essential for abdominal approaches, may increase some risks in older FTRP patients [1,3,14-16]. Perineal approaches are less invasive and potentially advantageous.

\section{Perineal approach}

The perineal approach is traditionally reserved for older patients with moderate/severe comorbidities, because this approach can be completed under local anesthesia and is usually well tolerated $[1,16]$. The perineal approach involves mucosal plication, anal encirclement, mucosal sleeve resection, and perineal rectosigmoidectomy [1].

Mucosal plication was first described by Gant in 1923 [17] and his theory was popularized by Miwa in 1962 [18]. The advantage of Gant's technique is its simplicity, but a higher recurrence rate of approximately $30 \%$ has been reported [18].

Anal encirclement using a silver wire was first described by Thiersch in 1891 [19]. This procedure has been performed often, but carries higher morbidity and recurrence rates [1]. Foreign-body reactions are a common complication that usually necessitates implant removal $[1,20]$.

Mucosal sleeve resection was first described by Delorme in 1900 [21]. This procedure is considered a treatment for shortsegmental FTRP [1], although no predictors of recurrence have been identified [22].

Perineal rectosigmoidectomy was first performed by Mikulicz, in 1889 [23], although the procedure was popularized by Altemeier et al in 1971 [24]. The procedure has spread worldwide since the early 1970s [1]; however, postoperative bleeding and anastomotic dehiscence are possible [1]. Note that this approach should be performed under spinal or epidural anesthesia, not under local anesthesia. Large resections of the rectocolon and mesentery require anastomosis, associated with tension (not poor vascularization); insufficient resection results in recurrence [1]. Low recurrence rates of $0-10 \%$ have been documented [1], although this rate increased to $18 \%$ in long-term follow-up studies [25]. An unsuccessful repair at the initial surgery was the only predictor of recurrence [25], and repeated colorectal resection via the perineal approach can be chosen for recurrent prolapse even after initial perineal colorectal resection [1].

\section{Abdominal approach by conventional laparotomy}

Ripstein and Lanter believed that FTRP resulted primarily from rectal intussusception and that this intussusception occurred because of a loss of the rectal attachments [26,27]. This belief led to a surgical technique that fixes the rectum to the sacrum, termed sacral fixation or rectopexy [26,27]. The authors initially described their procedures in 1963: they used the fascia lata to create a sling that would attach the rectum to the sacrum [26]. Subsequently, they modified their technique [28] to employ rectal fixation to the sacral promontory using an encircling sling of non-absorbable mesh [29]. This procedure involves mobilizing the rectum to the coccyx while dividing the lateral peritoneal attachments and preserving the lateral ligaments. While the rectum is retracted cranially, a $5-\mathrm{cm}$ piece of mesh is wrapped anteriorly around the rectum at the level of the peritoneal reflection and then sutured bilaterally to the presacral fascia, approximately $5 \mathrm{~cm}$ below the promontorium [1,26]. Anterior wrapping, which includes part of the rectal free wall, is known as the modified Ripstein procedure, and this procedure is now standard surgery for FTRP, with further modifications [1,2,29]. 
The mortality and recurrence rates for this procedure are relatively low [1]; however, it is associated with significant morbidity of up to $33 \%$ [1]. Wrapping too tightly causes bowel obstruction [1]. Furthermore, the anterior wall of the mesh is partially exposed to the peritoneal cavity [1], and moderate/ severe complications are associated with mesh placement. Local infection and erosion of important nearby tissues/organs (such as the bladder) develop easily [1].

Fixation of the rectum to the sacrum is designed to restore the physiological position of the rectum $[2,26]$ and thereby also correct the descensus of the pelvic floor [2]. Fixation can be achieved by simple suturing, stapling, or using mesh $[1,2,26]$. Mesh can be placed anteriorly, posteriorly, laterally, and around the rectum [2].

A suture method for rectopexy was first described by Sudeck in 1922 [2]. This procedure includes complete mobilization of the rectum to the level of the levators [2]. Dorsal mobilization of the rectum induces fibrosis, which helps fix and hold the rectum in place [30]. Although low recurrence rates are documented [31], the recurrence rate increased to $20 \%$ in longer follow-up studies [32].

The therapeutic potential of rectosigmoidectomy for FTRP was documented by Miles in 1933 [33]. Resection of redundant sigmoid colon combined with rectopexy was described by Frykman in 1955 [34]. Four essential steps were documented, as follows [34]: (i) complete mobilization of the rectum to the levator complex with the lateral ligaments left intact; (ii) elevation of the rectum with suture fixation to the presacral fascia just below the promontorium; (iii) obliteration of the cul-de-sac with suturing of the endopelvic fascia anteriorly to the rectum; and (iv) resection of the redundant sigmoid colon with an end-toend anastomosis. This procedure remains essentially the same today [1], and obliteration of the cul-de-sac is key [1]. Frykman and Goldberg believed that this procedure is highly effective for FTRP [2,35], based on the following morphological changes: (i) a fibrotic area develops around the anastomosis and the sacrum, which leads to a stronger rectal fixation to the sacrum; and (ii) the colon lies straighter [35]. This procedure improves obstipation rates, but anal leakage occurs in $4 \%$ of patients [36].

A technique using partial wrapping with mesh was designed to leave the surface of the rectum partially free [37]; mesh placement after complete rectal mobilization has been considered important [37-39]. To accomplish this goal, lateral rectopexy was first reported by Orr in 1947 [40]; later, lateral mesh rectopexy was documented as the Orr-Loygue procedure by Loygue et al in 1957 [37]. Postoperative mortality rates of up to $17 \%$ were reported $[41,42]$. If mesh is placed around the posterior circumference of the rectum $(2 / 3)$ and then fixed to the promontorium, the ventral third of the rectal circumference is spared, which avoids fibrosis and stenosis related to the mesh shrinking [38]. Posterior mesh rectopexy was first described by Wells in 1959 [38] and has a recurrence rate of $10 \%$ [43].

\section{Abdominal approach by laparoscopic surgery}

Laparoscopic rectopexy accompanied by suturing or resection has been described $[2-4,44]$, along with a laparoscopic technique without sutures using a sacral tacker [45]. In laparoscopic resection rectopexy, the rate of anastomotic leakage is up to $3 \%[2,44]$. To our knowledge, there is only one report of a laparoscopic approach for encircled or anterior mesh repair (i.e. laparoscopic modified Ripstein procedure) and no morbidity or recurrence was reported [46]. However, this laparoscopic procedure has not been evaluated in research studies. The modified Ripstein procedure appears dated in the current era of laparoscopic surgery, which has postoperative recurrence rates of up to $6 \%$ with lateral mesh rectopexy $[41,47]$ and up to $4 \%$ with posterior mesh rectopexy $[48,49]$.

An autonomic nerve-sparing rectopexy technique was first documented by D'Hoore et al in 2004 [5], based on the previous concept of rectovaginopexy described by Silvis et al in 1998 [50]. The dissection in this procedure is strictly ventral in the rectovaginal space to the pelvic floor; lateral or dorsal mobilization is not performed. The rectum is attached to the sacrum by mesh sutured to the anterior side of the rectum. Ventral dissection and positioning of the mesh has several advantages [4]: (i) a supra-anal rectocele can be corrected; (ii) the rectovaginal septum is reinforced, which prevents anterior recto-rectal intussusception, which may be an underlying mechanism leading to full rectal prolapse; and (iii) a colpopexy is performed. Avoiding all lateral or posterior mobilization preserves the autonomic nerves. This procedure is a comparably novel method adopted rapidly and many prospective series have reported good outcomes and postoperative function [2]. However, it is critical to note that reliable evidence had not been reported [2,51], while the reported postoperative morbidity rates are as high as 36\% [52]. In addition, the reported meshrelated complication rate is $4 \%$ [2].

\section{Mortality and morbidity}

When the transabdominal approach is chosen in patients older than 50 years, concurrent colorectal cancer should be ruled out to avoid unexpected postoperative complications and/or poor outcomes $[1,7,15]$. If mesh-related postoperative infection, erosion, dislocation, or pain occurs, removal of the infected foreign body, i.e. the implanted mesh, is the initial management [52-54].

Historically, many surgical procedures have been described for FTRP treatment [1,2,9]. The morbidity and mortality rates for each procedure are summarized in Table 1 [1,2,10,18,20,22,32,41-43,47-49,52-62].

\section{Recurrence rates}

Postoperative recurrence is a critical concern, and high recurrence rates have been documented [1]. Recurrence rates for each surgery are summarized in Table $1 \quad[1,2,10,18,20,22,32,41-43,47-49,52-62]$. We have employed our approach since 2006 and we have dealt with a total of 21 cases during approximately 12 years. Follow-up term is 
Table 1 Postoperative rates of morbidity, mortality and recurrence

\begin{tabular}{|c|c|c|c|c|c|}
\hline Approach & \multicolumn{2}{|c|}{ Advocate (year) } & Morbidity [\%] & Mortality [\%] & Recurrence [\%] \\
\hline \multicolumn{6}{|l|}{ Perineal approach } \\
\hline Mucosal plication & Gant & $(1923)$ & $0-23$ & 0 & $8-30$ \\
\hline Anal encirclement & Thiersch & $(1891)$ & 20 & 0 & $13-44$ \\
\hline Mucosal sleeve resection & Delorme & $(1900)$ & $4-33$ & $0-7$ & $6-26$ \\
\hline Rectosigmoidectomy & Altemeier & $(1971)$ & $5-24$ & $0-6$ & $0-18$ \\
\hline \multicolumn{6}{|l|}{ Abdominal approach } \\
\hline \multicolumn{6}{|l|}{ Conventional laparotomy } \\
\hline Suture rectopexy & Sudeck & $(1922)$ & $9-20$ & $0-4$ & $0-20$ \\
\hline Encircled/anterior mesh rectopexy & Ripstein & $(1963)$ & $4-33$ & $0-3$ & $0-12$ \\
\hline Rectopexy and resection & Frykman & $(1955)$ & $7-23$ & $0-7$ & $0-9$ \\
\hline Lateral mesh rectopexy & Orr-Loygue & $(1957)$ & $0-4$ & $0-17$ & $0-5$ \\
\hline Posterior mesh rectopexy & Wells & $(1959)$ & $0-28$ & $0-4$ & $0-10$ \\
\hline \multicolumn{6}{|l|}{ Laparoscopic surgery } \\
\hline Suture rectopexy & - & - & $9-19$ & 0 & $0-7$ \\
\hline Lateral mesh rectopexy & - & - & $0-5$ & 0 & $0-6$ \\
\hline Posterior mesh rectopexy & - & - & $0-14$ & 0 & $0-4$ \\
\hline Rectopexy and sigmoidectomy & - & - & $8-21$ & $0-1$ & $0-11$ \\
\hline Ventral rectopexy & D'Hoore & $(2004)$ & $10-36$ & 0 & $0-15$ \\
\hline
\end{tabular}

6.6 \pm 3.3 years (range 1.0-11.5 years). All patients were followed in the outpatient department or through inquiry contact, although four have already died due to other causes. We have no experience of any recurrences based on clinical (not radiological) diagnosis.

\section{Anesthesia for surgery}

Traditionally, the perineal approach has been used for older patients, because these patients are sometimes not candidates for general anesthesia [1,7]. Generally speaking, the perineal approach has lower morbidity and mortality rates, even in complicated older patients, but higher rates of recurrence [1,7]. One study found no differences in quality of life for patients undergoing different types of prolapse surgery [63].

Deep vein thrombosis may occur after abdominal surgery under general anesthesia, and often results in a poor clinical course. Therefore, postoperative anticoagulant prophylaxis against platelet and neutrophil aggregation is important [64-69].

\section{Laparoscopic surgery and the learning curve}

Laparoscopic rectopexy was first reported by Berman in 1992 [45] and has emerged as an efficient procedure for FTRP treatment $[14,47,54,70,71]$. Advanced laparoscopy and modern general anesthesia have made the abdominal approach more attractive, even for older patients [3,14]. Laparoscopic
FTRP techniques are currently available for the abdominal approach, although conventional open surgeries have been performed [9,11-14]. Studies have suggested that laparoscopic surgery has advantages over open surgery, including less pain, a shorter hospital stay, and faster recovery $[72,73]$.

A survey of the preferred method for FTRP treatment in over 50 countries revealed that $60 \%$ of surgeons would treat patients laparoscopically, $20 \%$ would chose an abdominal method via conventional laparotomy, and only $20 \%$ favored a perineal approach [74]. Laparoscopic rectopexy is the most popular treatment in Europe. Surgeons in North America favored laparoscopic resection rectopexy in 2013 [74] and laparoscopic ventral rectopexy is currently far more likely to be performed in 2017 [75].

The learning curve for laparoscopic colorectal surgery is approximately $150-200$ cases to achieve a constant level of proficiency [76,77]. Regarding FTRP, approximately 100 patients are required for good clinical and functional outcomes, even for an experienced colorectal surgeon [78].

Robotic surgery was first described by Munz et al in 2004 [79] and is an attractive new frontier [80].

\section{Recurrent prolapse}

Because of a significant recurrence rate, choosing the ideal therapeutic strategy to avoid recurrent prolapse is important $[1,81]$, and surgeons must be aware of each patient's details prior to surgery [1]. In particular, the most important 
determinant of secondary or additional surgery is the remaining blood supply [1], and patients who have previously undergone resection or who require two anastomoses are at risk for ischemia [1].

Repeated colorectal resection via the perineal approach can be chosen for recurrent prolapse after initial perineal colorectal resection [1]. Perineal rectosigmoidectomy is indicated for patients who suffer early recurrence of prolapse after another perineal repair, especially older or high-risk patients [16]. Fixation and suspension of the rectum via the abdominal approach is considered a reasonable alternative therapy for recurrent prolapse [1]. However, perineal rectosigmoidectomy should be avoided in patients who have previously undergone rectopexy via the abdominal approach [1], though this method may be available in patients after only a rectopexy.

\section{Cost-effectiveness}

When costs for operative time, staff, laparoscopic equipment, and hospital stay were included, laparoscopic surgery was found to be less costly than conventional laparotomy [82]. The shorter hospital stay in the laparoscopic group accounted for this saving.

\section{Current status}

No differences in quality of life were found in patients undergoing different types of prolapse surgery [63]. Therapeutic decisions must be individualized and must consider each patient's disease characteristics as well as the surgeon's experience [83]. The lack of high-quality evidence comparing the different techniques, together with the small sample sizes in included trials and their methodological weaknesses, severely limit the usefulness of this review for guiding practice $[2,63]$. It is impossible to identify or refute clinically important differences between the alternative surgical operations [63]. Long-term follow up with current studies and larger rigorous trials are needed to improve the evidence base and to define the optimum surgical treatment for FTRP $[2,63,81]$.

\section{Surgical procedure used in our institution}

Here, we described our laparoscopic procedures step by step in Figs. 1-8. General anesthesia with concurrent epidural anesthesia is instigated with the patient in the lithotomy position. Anal tone is routinely checked beforehand. After the establishment of carbon dioxide pneumoperitoneum through the umbilical port, a flexible laparoscope is introduced via the same port. A total of four working ports $(5 \mathrm{~mm})$ are placed. A deep Douglas' pouch is often observed. The ileum and cecum are isolated using gauze sponges to prevent interference in the surgical field. The uterus is usually elevated and
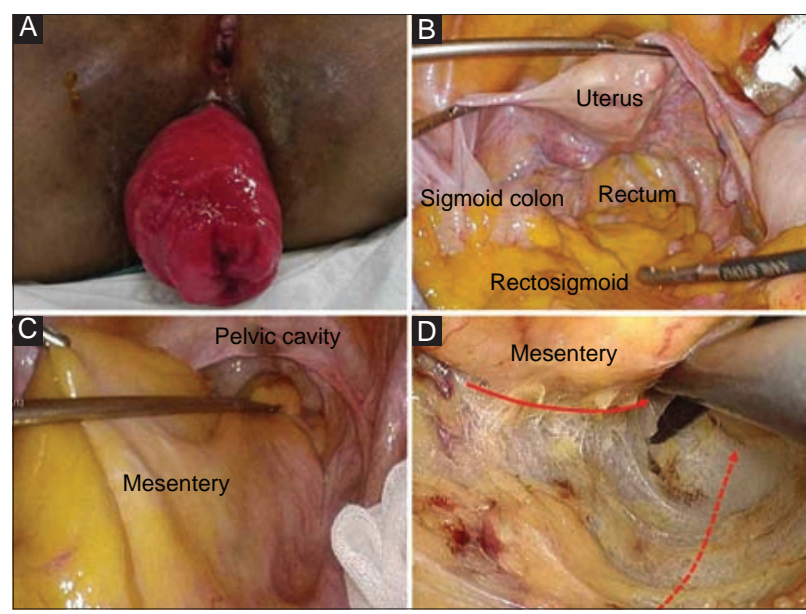

Figure 1 (A) General anesthesia with concurrent epidural anesthesia is performed with the patient in the lithotomy position. Anal tone is routinely checked beforehand. (B) A deep Douglas' pouch is often observed. (C, D) The rectum and mesentery are completely mobilized from the sacral promontory. The superficial dissectable/transectable layer (solid arrow), and not the deep dissectable/transectable layer (dotted arrow), should be traced to preserve the nerves

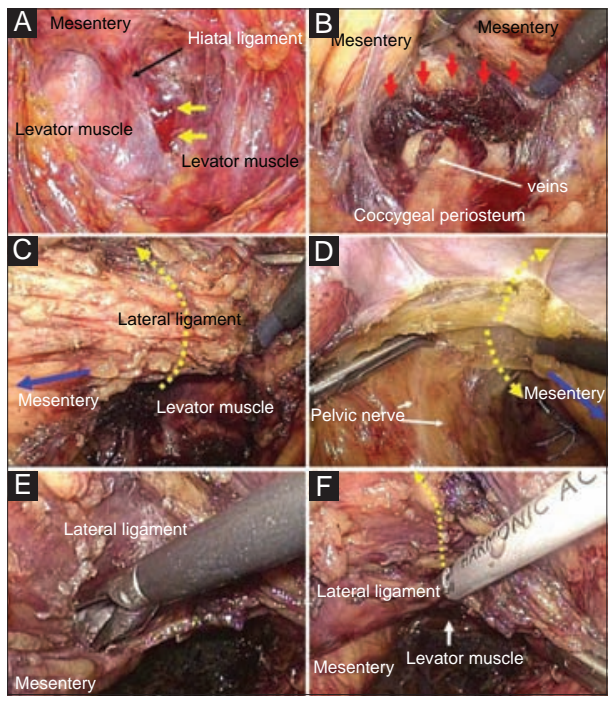

Figure 2 (A) The hiatal ligament bleeds easily (arrow). (B) Veins of the coccygeal periosteum also bleed easily (arrow). (C-F) The left lateral ligament is transected (dotted arrows) while the pelvic nerves and neurovascular bundle are preserved. The levator muscle is exposed under sufficient countertraction (blue arrow).

sutured to the abdominal wall to create an adequate surgical field. The rectum and mesentery are completely mobilized from the sacral promontory. The superficial dissectable/ transectable layer, and not the deep dissectable/transectable layer, should be traced to preserve the nerves. The ureters are observed bilaterally. The levator muscle is well exposed at the posterior side of the rectum. The hiatal ligament and veins of the coccygeal periosteum bleed easily. The lateral ligament is transected under adequate countertraction, while the pelvic nerves and neurovascular bundle are preserved. The levator muscle is well exposed bilaterally under sufficient 

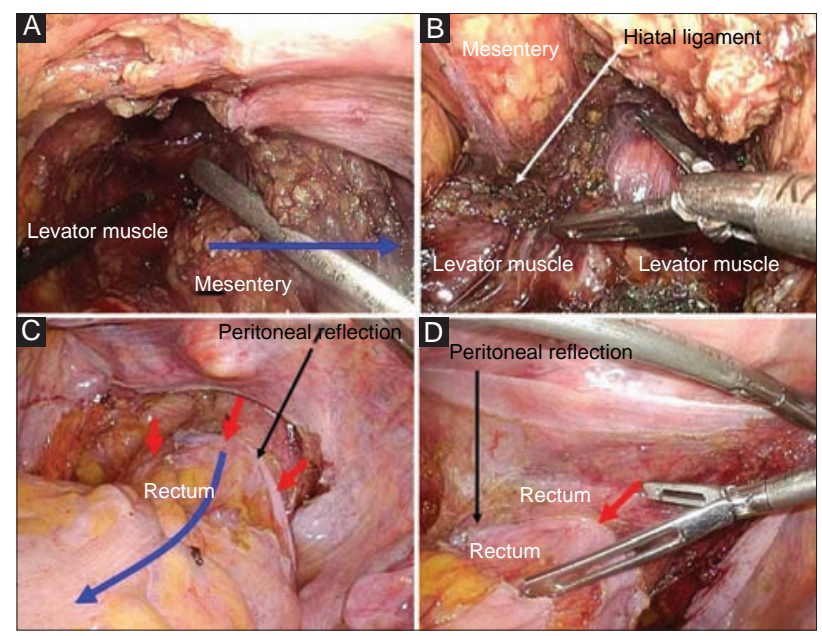

Figure 3 (A) The levator muscle is well exposed bilaterally under sufficient countertraction (blue arrow). (B) The exposed area is assessed using forceps. (C) The anterior rectal wall is mobilized sufficiently from its peritoneal reflection (red arrow) under sufficient countertraction (blue arrow). (D) The mobilized area is assessed using forceps. Anterior rectal dissection is completed to $2 \mathrm{~cm}$ below the peritoneal reflection (red arrow).
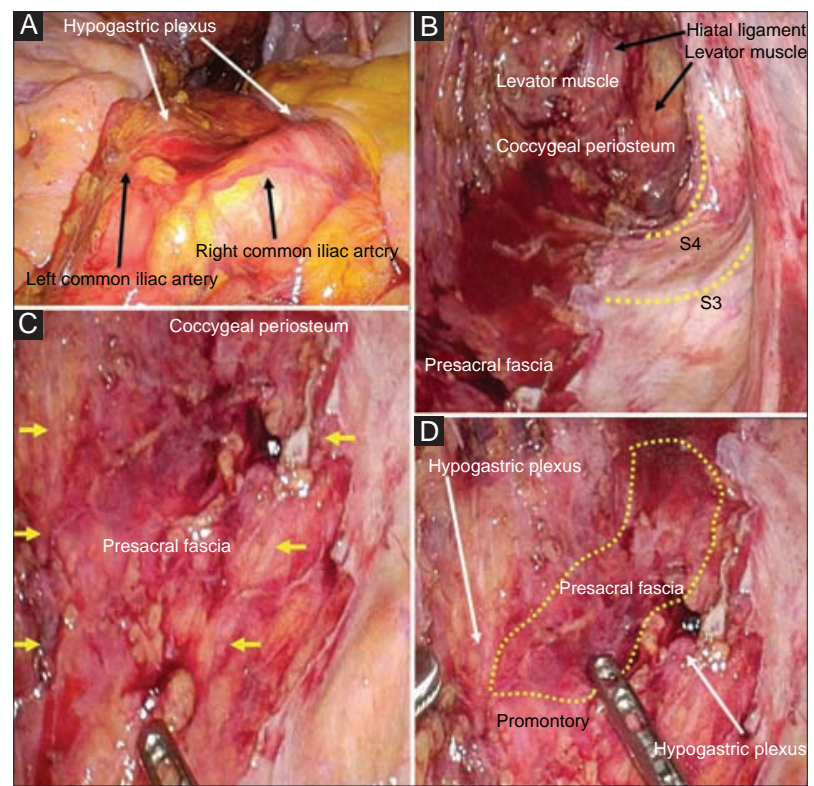

Figure 4 (A) The hypogastric plexus is preserved bilaterally. (B) Pelvic nerves are also preserved. (C) The preserved hypogastric plexus is confirmed (arrow). (D) The area of mesh fixation is estimated without injuring the nerves and vessels (dotted area).

countertraction. The exposed area is assessed using forceps. Rectal mobilization is maintained until the levator muscle is well exposed. The anterior rectal wall is mobilized sufficiently from its peritoneal reflection under sufficient countertraction. Connective tissue and Denonvillier's fascia are transected. The mobilized area is assessed using forceps, and anterior rectal dissection is completed to $2 \mathrm{~cm}$ below the peritoneal reflection by lifting the mobilized rectum cranially to the promontorium. The hypogastric plexus is preserved bilaterally.
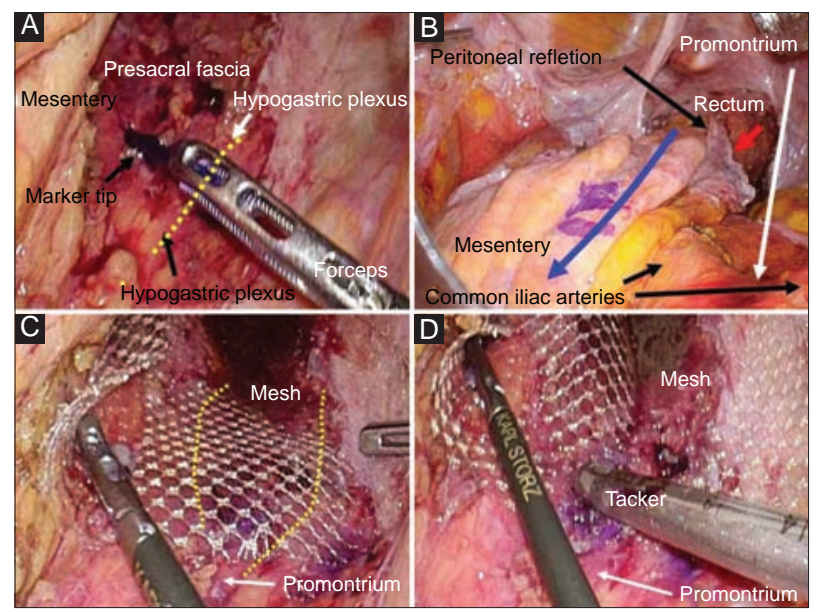

Figure 5 (A) Optimal points for mesh fixation on the presacral fascia are marked without injury to the nerves (dotted line) and vessels. (B) After the mobilized rectum has been elevated cranially to the promontorium (blue arrow), the optimal points for mesh fixation of the rectum are marked. The anterior wall is elevated (red arrow). (C) Mesh is inserted through the port. Nerves (dotted lines) and vessels on the sacrococcyx should be visible through the mesh to prevent tack injuries. (D) Mesh is fixed to the pre-sacrococcygeal fascia using absorbable tacks.

Pelvic nerves are also preserved. The area of mesh fixation is estimated without injury to the nerves and vessels. Optimal points for mesh fixation on the presacral fascia are marked without injuring the nerves and vessels. After mobilized rectum has been elevated cranially to the promontorium, the optimal points for mesh fixation of the rectum are marked. The anterior wall is elevated. Mesh is inserted through the port. Nerves and vessels on the sacrococcyx should be visible through the mesh to prevent tack injuries. Mesh is fixed to the pre-sacrococcygeal fascia using absorbable tacks (Securestrap; Ethicon Inc., Cincinnati, OH, USA). The mobilized rectum is lifted cranially to the promontorium. The seromuscular layer of the left rectal wall is sutured to the mesh using a small number of interrupted non-absorbable polypropylene sutures (3-0 Prolene, SH-1, 90 cm; Ethicon Inc., Cincinnati, $\mathrm{OH}$, USA). Pelvic nerves are preserved. The seromuscular layer of the rectal wall is sutured to the mesh using a small number of interrupted non-absorbable polypropylene sutures. The peritoneum is closed bilaterally to prevent mesh exposure. A suture is placed for peritoneal closure, and staples can be used to close the peritoneum (arrows). The redundant sigmoid colon and mobilized rectosigmoid are visible. The mesentery of the mobilized rectosigmoid is elevated and the cul-de-sac of the pelvic floor is observed. Obliterating the cul-de-sac is necessary to prevent unexpected postoperative complications after surgery. The cul-de-sac is closed by interrupted or running suture using non-absorbable polypropylene (3-0 Prolene; Ethicon Inc.). The FTRP is resolved, and a normalized anus is seen.

Here, key points and pitfalls are listed. The lateral ligament should be transected bilaterally to adequately mobilize the rectum and the posterior and lateral rectal walls should be well exposed. The pelvic nerves and neurovascular bundle should be 

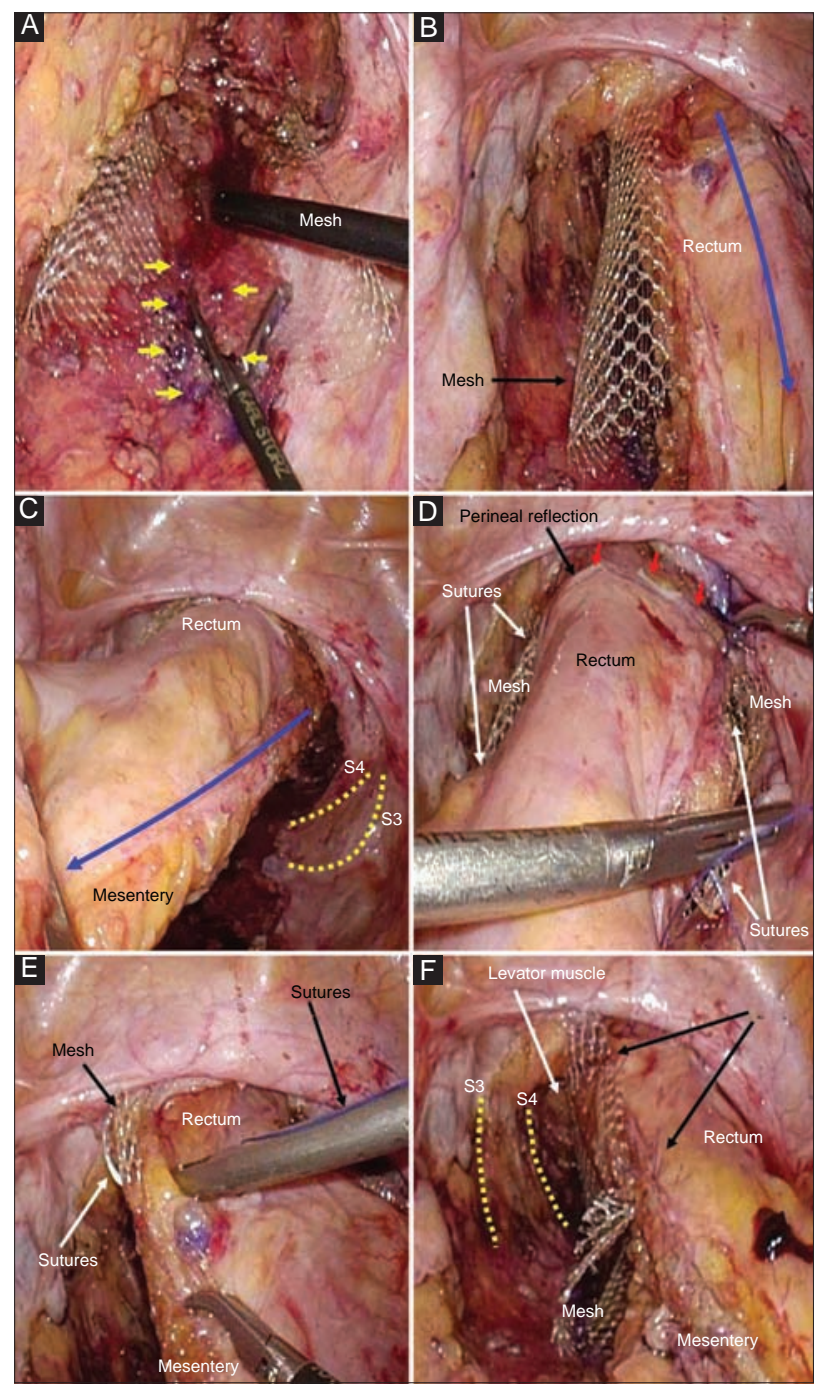

Figure 6 (A) Mesh is fixed to the pre-sacrococcygeal fascia (arrows) using absorbable tacks. (B, C) The mobilized rectum is lifted cranially to the promontorium (blue arrow). Pelvic nerves (dotted lines) are preserved. (D-F) The seromuscular layer of the rectal wall is sutured to the mesh using a small number of interrupted non-absorbable polypropylene sutures. Pelvic nerves (dotted lines) are preserved. The anterior wall is elevated (red arrows).

preserved. The levator muscle is exposed approximately $5 \mathrm{~cm}$ from the lateral fascia to the hiatal ligament. Mesh is fixed to the pre-sacrococcygeal fascia using absorbable tacks, without injuring the nerves and vessels. The hypogastric plexus, pelvic nerves, and pre-sacrococcygeal vessels must be visualized through the mesh before fixation. The levator muscle should be well exposed, and the peritoneum should be closed bilaterally to prevent mesh exposure. The anterior wall must also be well elevated.

Of course, we have demonstrated our individual-tailored approach. This represents our experience in a single institution and our views may be affected by various biases. Hence, we understand that our conclusions must be drawn with extreme caution.

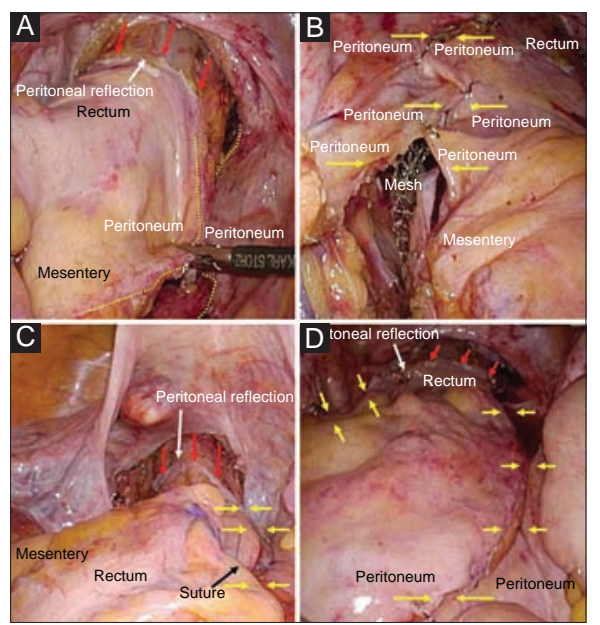

Figure 7 (A) The peritoneum (dotted lines) is closed bilaterally to prevent mesh exposure, and the anterior wall is elevated (red arrows). (B) The peritoneum is closed bilaterally (yellow arrows) to prevent mesh exposure. (C) A suture is placed for peritoneal closure (yellow arrows) to prevent mesh exposure. The anterior wall is well elevated (red arrows). (D) Staples can be used to close the peritoneum. The peritoneum should be closed bilaterally (yellow arrows) to prevent mesh exposure. The anterior wall is well elevated (red arrows).
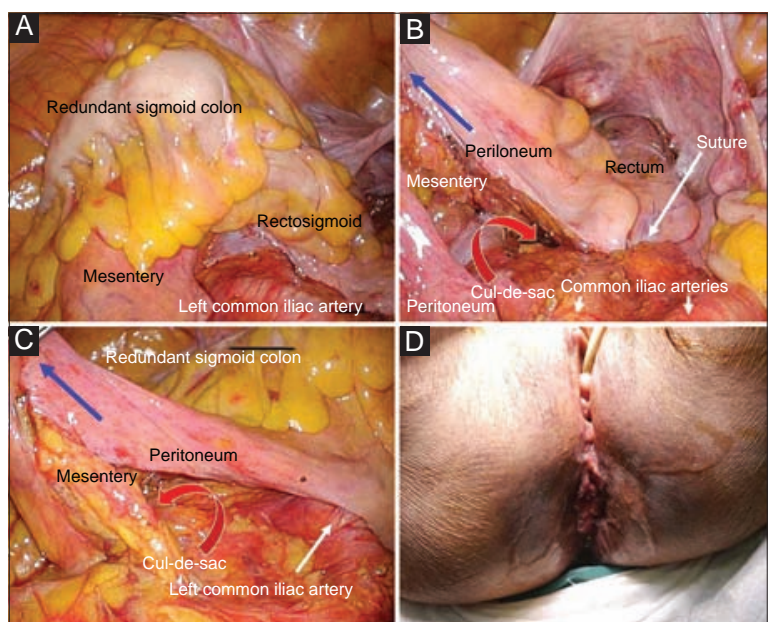

Figure 8 (A) The redundant sigmoid colon and mobilized rectosigmoid are visible. (B) The mesentery of the mobilized rectosigmoid is elevated (blue arrow) and the cul-de-sac of the pelvic floor can be observed (red arrow). Obliterating the cul-de-sac is necessary to prevent unexpected postoperative complications after surgery. (C) The mesentery of the redundant sigmoid colon is elevated (blue arrow) and the cranial culde-sac is visible (red arrow). Obliterating the cul-de-sac is necessary to prevent unexpected postoperative complications after surgery. (D) The full-thickness rectal prolapse is resolved, and a normalized anus can be seen.

\section{Discussion}

Minimizing morbidity and mortality are important even in older patients, as are reducing recurrence rates and obtaining functional outcomes [1]. To address these goals, many studies have evaluated postoperative morbidity. Postoperative 
complication with bowel resection, i.e., leakage, occurs in $3-4 \%$ of patients $[2,22,36]$, and peritonitis causes subsequent severe complications. Obliterating the cul-de-sac by suturing is important [1], although some surgeons choose to omit this important step [1]. Note that perineal closure is also important.

Sufficient rectal mobilization from the sacral promontorium is important to prevent recurrence [3,84]. Several studies have evaluated managing the lateral ligaments during surgery (i.e., division or preservation) $[1,11]$. Dividing the lateral rectal ligaments was associated with a decreased recurrence rate of $0 \%$, but an increased constipation rate of $67 \%$ [11]. Lateral ligament division during rectopexy causes constipation but prevents recurrence, based on a prospective randomized study [84]. If the lateral stalks are divided, postoperative constipation may occur. Some medications may be required, though we did not have any experience of refractory and intractable constipation after surgery.

The less invasive perineal approach can be performed easily, even in patients with higher risks for general anesthesia. However, the recurrence rate for the perineal approach is higher than for the transabdominal approach [14]; therefore, the latter is considered the first choice for FTRP treatment $[14,15]$. Mesh fixation for rectopexy in conventional open surgery was originally described as Ripstein's procedure in 1963 [26], and was subsequently modified several times. Ripstein's procedure has been performed worldwide but has a significant morbidity rate [1]. Ways of modifying the mesh fixation, such as posterior wrapping and using a laparoscopic approach, have been described [86], but mesh-related postoperative complications, such as tissue erosion, infection, and mesh migration, are critical problems [75]. Abdominal rectopexy with sigmoid colectomy was developed by Frykman and Goldberg [34,35] and subsequent studies have evaluated the usefulness of sigmoidectomy [1]. Resecting the sigmoid colon requires colonic anastomosis, which carries a risk of anastomotic leakage and subsequent fatal complications. The best results are obtained by fixing the mobilized rectum in the hollow of the sacrum, as described by Wells in 1959 or by Ripstein in 1969 [85-87], although there is a lack of high-quality evidence for choosing between surgical options $[2,63,81,83]$.

With developments in laparoscopy and surgical instruments, laparoscopic surgery is now performed worldwide. The safety and feasibility of the laparoscopic transabdominal approach for FTRP has been demonstrated in several studies [14,88-90], and the laparoscopic transabdominal approach is a safe, reliable and effective procedure associated with minimal morbidity and low recurrence rates [14,88-90].

Safe surgery with good clinical outcomes should be chosen for complicated older patients with FTRP, considering that general anesthesia is required for the abdominal approach. Laparoscopic surgery has great potential in FTRP treatment.

\section{References}

1. Garely AD, Krieger BR, Ky AJ. Rectal prolapse. In: Cameron JL, Cameron AM (editors): Current surgical therapy. Elsevier
Saunders: Philadelphia; 2014, pp. 190-194.

2. Rickert A, Kienle P. Laparoscopic surgery for rectal prolapse and pelvic floor disorders. World $J$ Gastrointest Endosc 2015;7:1045-1054.

3. Yasukwa D, Hori T, Machimoto T, et al. Outcome of a modified laparoscopic suture rectopexy for rectal prolapse with the use of a single or double suture: A case series of 15 patients. Am J Case Rep 2017;18:599-604.

4. Van Geluwe B, Wolthuis A, D’Hoore A. Laparoscopy for pelvic floor disorders. Best Pract Res Clin Gastroenterol 2014;28:69-80.

5. D'Hoore A, Cadoni R, Penninckx F. Long-term outcome of laparoscopic ventral rectopexy for total rectal prolapse. Br J Surg 2004:91:1500-1505.

6. Emile SH, Elfeki HA, Youssef M, Farid M, Wexner SD. Abdominal rectopexy for the treatment of internal rectal prolapse: a systematic review and meta-analysis. Colorectal Dis 2017;19:O13-O24.

7. Tiengtianthum R, Jensen CC, Goldberg SM, Mellgren A. Clinical outcomes of perineal proctectomy among patients of advanced age. Dis Colon Rectum 2014;57:1298-1303.

8. Marceau C, Parc Y, Debroux E, Tiret E, Parc R. Complete rectal prolapse in young patients: psychiatric disease a risk factor of poor outcome. Colorectal Dis 2005;7:360-365.

9. Wu JS. Rectal prolapse: a historical perspective. Curr Probl Surg 2009;46:602-716.

10. Theuerkauf FJ, Jr., Beahrs OH, Hill JR. Rectal prolapse. Causation and surgical treatment. Ann Surg 1970;171:819-835.

11. Tou S, Brown SR, Malik AI, Nelson RL. Surgery for complete rectal prolapse in adults. Cochrane Database Syst Rev 2008:CD001758.

12. Ramage L, Georgiou P, Tekkis P, Tan E. Is robotic ventral mesh rectopexy better than laparoscopy in the treatment of rectal prolapse and obstructed defecation? A meta-analysis. Tech Coloproctol 2015;19:381-389.

13. van Iersel JJ, Paulides TJ, Verheijen PM, Lumley JW, Broeders IA, Consten EC. Current status of laparoscopic and robotic ventral mesh rectopexy for external and internal rectal prolapse. World $J$ Gastroenterol 2016;22:4977-4987.

14. Murphy PB, Wanis K, Schlachta CM, Alkhamesi NA. Systematic review on recent advances in the surgical management of rectal prolapse. Minerva Chir 2017;72:71-80.

15. van Iersel JJ, Consten EC. Ventral mesh rectopexy for rectal prolapse: level-I evidence. Lancet Gastroenterol Hepatol 2016;1:264265.

16. Takesue Y, Yokoyama T, Murakami Y, et al. The effectiveness of perineal rectosigmoidectomy for the treatment of rectal prolapse in elderly and high-risk patients. Surg Today 1999;29:290-293.

17. Gant S. The ileocolic angle, appendix, colon, sigmoid flexure, rectum, anus, buttocks, and sacrococcygeal region. Disease of the rectum, anus and colon Volume II. W.B. Saunders Company: Philadelphia; 1923, pp. 22-57.

18. Yamana T, Iwadare J. Mucosal plication (Gant-Miwa procedure) with anal encircling for rectal prolapse-a review of the Japanese experience. Dis Colon Rectum 2003;46:S94-99.

19. Carrasco A. Thiersch (1891). Contribution a l'etude du Prolapsus du Rectum. Masson: Paris; 1943.

20. Poole GV, Jr., Pennell TC, Myers RT, Hightower F. Modified Thiersch operation for rectal prolapse. Technique and results. Am Surg 1985;51:226-229.

21. Delorme R. Sur le traitement des prolapses du rectum totaux pour l'excision de la muscueuse rectal ou rectolique. Bull Mem Soc Chir Paris 1900;26:499-518.

22. Lieberth M, Kondylis LA, Reilly JC, Kondylis PD. The Delorme repair for full-thickness rectal prolapse: a retrospective review. Am J Surg 2009;197:418-423.

23. Mikulicz J. Zur operation behandlung des prolapsus recti et cold invaginati. Arch Klin Chir 1889;38:74-97.

24. Altemeier WA, Culbertson WR, Schowengerdt C, Hunt J. Nineteen 
years' experience with the one-stage perineal repair of rectal prolapse. Ann Surg 1971;173:993-1006.

25. Altomare DF, Binda G, Ganio E, De Nardi P, Giamundo P, Pescatori M. Long-term outcome of Altemeier's procedure for rectal prolapse. Dis Colon Rectum 2009;52:698-703.

26. Ripstein CB, Lanter B. Etiology and surgical therapy of massive prolapse of the rectum. Ann Surg 1963;157:259-264.

27. Ripstein CB. Treatment of massive rectal prolapse. Am J Surg 1952;83:68-71.

28. McMahan JD, Ripstein CB. Rectal prolapse. An update on the rectal sling procedure. Am Surg 1987;53:37-40.

29. Bartolo DC. Gastroenterological options in faecal incontinence. Ann Chir 1991;45:590-598.

30. Matzel KE, Heuer S, Zhang W. Rectal prolapse. Abdominal or local approach. Chirurg 2008;79:444-451.

31. Wilson J, Engledow A, Crosbie J, Arulampalam T, Motson R. Laparoscopic nonresectional suture rectopexy in the management of full-thickness rectal prolapse: substantive retrospective series. Surg Endosc 2011;25:1062-1064.

32. Foppa C, Martinek L, Arnaud JP, Bergamaschi R. Ten-year follow up after laparoscopic suture rectopexy for full-thickness rectal prolapse. Colorectal Dis 2014;16:809-814.

33. Miles WE. Recto-sigmoidectomy as a method of treatment for procidentia recti. Proc R Soc Med 1933;26:1445-1448.

34. Frykman HM. Abdominal proctopexy and primary sigmoid resection for rectal procidentia. Am J Surg 1955;90:780-789.

35. Frykman HM, Goldberg SM. The surgical treatment of rectal procidentia. Surg Gynecol Obstet 1969;129:1225-1230.

36. Kiene S. Surgical methods in anal and rectal prolapse. Langenbecks Arch Chir Suppl II Verh Dtsch Ges Chir 1989:757-764.

37. Loygue J, Cerbonnet G. Surgical treatment of total prolapse of the rectum by rectopexy following the Orr technic; based on 14 case reports. Mem Acad Chir (Paris) 1957;83:325-329.

38. Wells C. New operation for rectal prolapse. Proc R Soc Med 1959;52:602-603.

39. Ripstein CB. A simple, effective operation for rectal prolapse. Postgrad Med 1969;45:201-204.

40. Orr TG. A'suspension operation for prolapse of the rectum. Ann Surg 1947;126:833-840.

41. Ratelle R, Vollant S, Peloquin AB, Gravel D. Abdominal rectopexy (Orr-Loygue) in rectal prolapse: celioscopic approach or conventional surgery. Ann Chir 1994;48:679-684.

42. Caronia FP, Cortese E, Mosnier H. Laparoscopic rectopexy: our experience in the treatment of complete rectal prolapse. G Chir 1999;20:311-313.

43. Atkinson KG, Taylor DC. Wells procedure for complete rectal prolapse. A ten-year experience. Dis Colon Rectum 1984;27:96-98.

44. Stevenson AR, Stitz RW, Lumley JW. Laparoscopic-assisted resection-rectopexy for rectal prolapse: early and medium followup. Dis Colon Rectum 1998;41:46-54.

45. Berman IR. Sutureless laparoscopic rectopexy for procidentia. Technique and implications. Dis Colon Rectum 1992;35:689-693.

46. Kusminsky RE, Tiley EH, Boland JP. Laparoscopic Ripstein procedure. Surg Laparosc Endosc 1992;2:346-347.

47. Lechaux D, Trebuchet G, Siproudhis L, Campion JP. Laparoscopic rectopexy for full-thickness rectal prolapse: a single-institution retrospective study evaluating surgical outcome. Surg Endosc 2005; 19:514-518.

48. Dulucq JL, Wintringer P, Mahajna A. Clinical and functional outcome of laparoscopic posterior rectopexy (Wells) for fullthickness rectal prolapse. A prospective study. Surg Endosc 2007;21:2226-2230.

49. Madbouly KM, Senagore AJ, Delaney CP, Duepree HJ, Brady KM, Fazio VW. Clinically based management of rectal prolapse. Surg Endosc 2003;17:99-103.

50. Silvis R, Gooszen HG, Kahraman T, et al. Novel approach to combined defaecation and micturition disorders with rectovaginovesicopexy. Br J Surg 1998;85:813-817.

51. Lundby L, Laurberg S. Laparoscopic ventral mesh rectopexy for obstructed defaecation syndrome: time for a critical appraisal. Colorectal Dis 2015;17:102-103.

52. Naeem M, Anwer M, Qureshi MS. Short term outcome of laparoscopic ventral rectopexy for rectal prolapse. Pak J Med Sci 2016;32:875-879.

53. Ross AH, Thomson JP. Management of infection after prosthetic abdominal rectopexy (Wells' procedure). BrJ Surg 1989;76:610-612.

54. Consten EC, van Iersel JJ, Verheijen PM, Broeders IA, Wolthuis AM, D'Hoore A. Long-term Outcome After Laparoscopic Ventral Mesh Rectopexy: An Observational Study of 919 Consecutive Patients. Ann Surg 2015;262:742-747.

55. Shen Z, Yang GG, Zhang XF, Qiu JM, Yu YY. Clinical analysis of 31 cases with rectal prolapse undergoing modified Gant-Miwa procedure and anal encircling. Zhonghua Wei Chang Wai Ke Za Zhi 2013;16:641-644.

56. Watkins BP, Landercasper J, Belzer GE, et al. Long-term follow-up of the modified Delorme procedure for rectal prolapse. Arch Surg 2003;138:498-502.

57. Flum AS, Golladay ES, Teitelbaum DH. Recurrent rectal prolapse following primary surgical treatment. Pediatr Surg Int 2010;26:427-431.

58. Marchal F, Bresler L, Ayav A, et al. Long-term results of Delorme's procedure and Orr-Loygue rectopexy to treat complete rectal prolapse. Dis Colon Rectum 2005;48:1785-1790.

59. Albayati S, Morgan MJ, Turner CE. Laparoscopic ventral rectopexy for rectal prolapse and rectal intussusception using a biological mesh. Colorectal Dis 2017; In press.

60. Fu CW, Stevenson AR. Risk factors for recurrence after laparoscopic ventral rectopexy. Dis Colon Rectum 2017;60:178-186.

61. Loygue J, Nordlinger B, Cunci O, Malafosse M, Huguet C, Parc R. Rectopexy to the promontory for the treatment of rectal prolapse. Report of 257 cases. Dis Colon Rectum 1984;27:356-359.

62. Graham W, Clegg JF, Taylor V. Complete rectal prolapse: repair by a simple technique. Ann R Coll Surg Engl 1984;66:87-89.

63. Tou S, Brown SR, Nelson RL. Surgery for complete (fullthickness) rectal prolapse in adults. Cochrane Database Syst Rev 2015:CD001758.

64. Hashimoto D, Nakagawa S, Umezaki N, et al. Efficacy and safety of postoperative anticoagulation prophylaxis with enoxaparin in patients undergoing pancreatic surgery: A prospective trial and literature review. Pancreatology 2017;17:464-470.

65. Sakon M, Maehara Y, Yoshikawa H, Akaza H. Incidence of venous thromboembolism following major abdominal surgery: a multicenter, prospective epidemiological study in Japan. J Thromb Haemost 2006;4:581-586.

66. Sakon M, Kobayashi T, Shimazui T. Efficacy and safety of enoxaparin in Japanese patients undergoing curative abdominal or pelvic cancer surgery: results from a multicenter, randomized, open-label study. Thromb Res 2010;125:e65-70.

67. Fuji T, Ochi T, Niwa S, Fujita S. Prevention of postoperative venous thromboembolism in Japanese patients undergoing total hip or knee arthroplasty: two randomized, double-blind, placebocontrolled studies with three dosage regimens of enoxaparin. J Orthop Sci 2008;13:442-451.

68. Ishikawa S, Miyashita T, Inokuchi M, et al. Platelets surrounding primary tumor cells are related to chemoresistance. Oncol Rep 2016;36:787-794.

69. Sakai S, Tajima H, Miyashita T, et al. Sivelestat sodium hydrate inhibits neutrophil migration to the vessel wall and suppresses hepatic ischemia-reperfusion injury. Dig Dis Sci 2014;59:787-794.

70. Faucheron JL, Trilling B, Girard E, Sage PY, Barbois S, Reche F. Anterior rectopexy for full-thickness rectal prolapse: Technical and functional results. World J Gastroenterol 2015;21:5049-5055. 
71. Luglio G, Tarquini R, Giglio MC, et al. Ventral mesh rectopexy versus conventional suture technique: a single-institutional experience. Aging Clin Exp Res 2017;29:79-82.

72. Purkayastha S, Tekkis P, Athanasiou T, et al. A comparison of open vs. laparoscopic abdominal rectopexy for fullthickness rectal prolapse: a meta-analysis. Dis Colon Rectum 2005;48:1930-1940.

73. Magruder JT, Efron JE, Wick EC, Gearhart SL. Laparoscopic rectopexy for rectal prolapse to reduce surgical-site infections and length of stay. World J Surg 2013;37:1110-1114.

74. Formijne Jonkers HA, Draaisma WA, Wexner SD, et al. Evaluation and surgical treatment of rectal prolapse: an international survey. Colorectal Dis 2013;15:115-119.

75. Joubert K, Laryea JA. Abdominal approaches to rectal prolapse. Clin Colon Rectal Surg 2017;30:57-62.

76. Miskovic D, Ni M, Wyles SM, Tekkis P, Hanna GB. Learning curve and case selection in laparoscopic colorectal surgery: systematic review and international multicenter analysis of 4852 cases. Dis Colon Rectum 2012;55:1300-1310.

77. Kayano H, Okuda J, Tanaka K, Kondo K, Tanigawa N. Evaluation of the learning curve in laparoscopic low anterior resection for rectal cancer. Surg Endosc 2011;25:2972-2979.

78. Mackenzie H, Dixon AR. Proficiency gain curve and predictors of outcome for laparoscopic ventral mesh rectopexy. Surgery 2014;156:158-167.

79. Munz Y, Moorthy K, Kudchadkar R, et al. Robotic assisted rectopexy. Am J Surg 2004;187:88-92.

80. Sajadi KP, Goldman HB. Robotic pelvic organ prolapse surgery. Nat Rev Urol 2015;12:216-224.

81. Hotouras A, Ribas Y, Zakeri S, et al. A systematic review of the literature on the surgical management of recurrent rectal prolapse. Colorectal Dis 2015;17:657-664.

82. Salkeld G, Bagia M, Solomon M. Economic impact of laparoscopic versus open abdominal rectopexy. Br J Surg 2004;91:1188-1191.

83. Schiedeck TH. Complications after rectal prolapse surgery. Chirurg 2015;86:747-751.

84. Speakman CT, Madden MV, Nicholls RJ, Kamm MA. Lateral ligament division during rectopexy causes constipation but prevents recurrence: results of a prospective randomized study. Br J Surg 1991;78:1431-1433.

85. Berk G. Rectal prolapse. Clinical studies on rectal prolapse. Chirurg 1979;50:173-179.

86. Scaglia M, Ribero F, Comotti F, Campra D, Delaini GG, Hulten L. The functional and manometric results of 2 surgical methods of posterior abdominal rectopexy. Minerva Chir 1994;49:383-392.

87. Scaglia M, Fasth S, Hallgren T, Nordgren S, Oresland T, Hultén L. Abdominal rectopexy for rectal prolapse. Influence of surgical technique on functional outcome. Dis Colon Rectum 1994;37:805-813.

88. Bloemendaal AL, Mishra A, Nicholson GA, et al. Laparoscopic rectopexy is feasible and safe in the emergency admission setting. Colorectal Dis 2015;17:O198-201.

89. Lundby L, Iversen LH, Buntzen S, Wara P, Hoyer K, Laurberg S. Bowel function after laparoscopic posterior sutured rectopexy versus ventral mesh rectopexy for rectal prolapse: a double-blind, randomised single-centre study. Lancet Gastroenterol Hepatol 2016;1:291-297.

90. Rose J, Schneider C, Scheidbach H, et al. Laparoscopic treatment of rectal prolapse: experience gained in a prospective multicenter study. Langenbecks Arch Surg 2002;387:130-137. 